\title{
Una visión actual del constructivismo
}

\section{A Current View of Constructivism}

\author{
Tomás Caycho
}

Universidad Privada del Norte, Lima, Perú.

\author{
Recibido 11-02-17 \\ Aprobado 05-05-17 \\ En Línea 09-05-17
}

\section{Correspondencia}

Email: tomas.caycho@upn.pe

\section{Citar como:}

Caycho, T. (2017). Una vision actual del constructivismo. Propósitos y Representaciones, 5(2). 475 - 482. doi: http://dx.doi.org/10.20511/ pyr2017.v5n2.159

(C) Universidad San Ignacio de Loyola, Vicerrectorado de Investigación, 2017.

(cc) BY-NC-ND Este artículo se distribuye bajo licencia CC BY-NC-ND 4.0 Internacional (http://creativecommons.org/licenses/by-nc-nd/4.0/). 
Frisancho, S. (Ed.) (2016). Ensayos Constructivista. Lima: Fondo Editorial de la PUCP. ISBN: 978-612-317-181-0.

El objetivo de esta reseña es analizar los avances del constructivismo y sus principales aportes a la educación y las ciencias sociales en general, a partir de los argumentado en los ocho capítulos del libro Ensayos Constructivistas, editado por la Dra. Susana Frisancho. Antes de la lectura del libro la hipótesis general que nos motiva es que en los últimos años, los aportes del constructivismo han ido de la mano de las nuevas necesidades educativas a nivel mundial.

Antes de pasar al libro, dediquemos unas líneas a la editora. La Dra. Susana Frisancho es una de las más importantes psicólogas del Perú, con estudios de psicología en la Pontificia Universidad Católica del Perú (PUCP) y Estados Unidos, es especialista en temas de desarrollo cognitivo, desarrollo moral, constructivismo y otros relacionados a la educación. Bajo su iniciativa, en el 2011, la PUCP organizó un encuentro de investigadores interesados en la teoría piagetana. Este evento es la génesis del libro que comentamos ahora.

Ensayos constructivistas resume un conjunto de capítulos relacionados con el estudio del constructivismo desde diferentes perspectivas y derivados de diversos contextos socioculturales. El libro tiene como objetivo brindar información acerca de la importancia del constructivismo, como marco teórico y epistemológico, del trabajo profesional y de investigación del psicólogo y educador. Este objetivo es aún más importante si tomamos en cuenta que el constructivismo ha sido por muchos años mal comprendido.

El prólogo es escrito por uno de los principales representantes del constructivismo a nivel mundial, el español Juan Delval. En él, Delval aclara que el constructivismo no es una teoría psicológica sino una teoría epistemológica con aplicaciones en la psicología y la educación, donde el punto central radica en las explicaciones internas acerca de la formación del conocimiento, específicamente de las transformaciones al interior del 
sujeto a partir del nuevo conocimiento adquirido como resultado de la experiencia. Además, si bien se pueden mencionar diversos antecedentes del constructivismo como los escritos de Kant, el constructivismo actual se forja bajo los planteamientos de Jean Piaget a partir de la necesidad de tener una explicación, diferente a las corrientes innatistas o espiritistas, de la génesis del conocimiento como resultado de la una interacción constante entre el sujeto y la realidad.

Como se mencionó líneas arriba, el libro está compuesto por ocho capítulos, a parte del prólogo de Delval, provenientes de autores de España, Perú, Brasil, Argentina y México. Los capítulos abordan, junto con la perspectiva constructivista, una visión sociohistórica, permitiendo de esta manera, el abordaje de diferentes problemas. El primer capítulo se centra en la revisión de las principales características del constructivismo como interacción entre sujeto y contexto a partir de una perspectiva psicológica y epistemológica, brindando a su vez aplicaciones en el ámbito educativo. El segundo capítulo aborda el papel de la teoría en el desarrollo del método clínico brindando evidencia para su adecuada aplicación en diferentes contextos. Enseguida, el tercer capítulo, analiza el problema de la toma de conciencia de la propia actividad, el cual es un proceso básico e importante para la diferenciación entre lo que se hace y lo que se comprende. El cuarto capítulo plantea nuevos problemas acerca del tema de la toma conciencia. Así analiza el problema de la causalidad y el empleo del método dialecticodidáctico y el conflicto cognitivo para el análisis de las explicaciones. E1 estudio de la moral y su aporte a la pedagogía es estudiado en el quinto capítulo. Se sugiere aquí una redefinición del papel del docente como mediador entre los estudiantes y los objetos de conocimiento.

El sexto capítulo diserta el papel del contexto cultural en el proceso de construcción del conocimiento a partir del análisis del problema de la moral. Luego, el penúltimo capítulo aborda el empleo de las historias y cuentos como instrumentos pedagógicos desde una perspectiva psicológica. Finalmente, el último capítulo se centra en el estudio del papel de los diarios 
personales, escritos por niños mexicanos y españoles, en el desarrollo del pensamiento narrativo como expresión de la organización del pensamiento y la interacción social.

La sensación al pasar de capítulo a capítulo es el de dinamismo entre contextos, tiempos y perspectivas teóricas y metodológicas. Este dinamismo contribuye a recalcar el tema fundamental del libro: el constructivismo. Para los estudiosos en temas educativos, el libro posee algunos atractivos importantes, conclusiones y referencias bibliográficas actualizadas por cada uno de los capítulos.

El libro presenta un orden de la información, con un estilo narrativo que atrae al lector y que presenta una visión de conjunta del constructivismo en el ámbito de las ciencias sociales. En conclusión, el libro es testimonio de la utilidad del constructivismo en la actualidad. Es de esperar, por tanto, que la edición de libros como éste se incremente en beneficio de todos los interesados en psicología cognitiva y constructivismo. 